\title{
/STUDIOMDA Wayfinding Design e uma análise sobre o projeto para o Centro Cultural Univates
}

\author{
/STUDIOMDA Wayfinding Design and an analysis on the project for Centro Cultural \\ Univates
}

COSSIO, Gustavo; Mestre em Design (Universidade Federal do Rio Grande do Sul - UFRGS);

dsgcossio@gmail.com

\section{Resumo}

A investigação trata sobre um escritório de design no sul do Brasil, especializado em sinalização e wayfinding. A partir do reconhecimento de uma trajetória que contabiliza vinte e cinco anos de experiência, o objetivo é indicar a contribuição do /STUDIOMDA para uma cultura de design em âmbito regional, uma vez que desenvolve projetos para espaços e públicos diversos, nos setores residencial, comercial e cultural. De modo a exemplificar a atuação do escritório, a análise enfatiza o desenvolvimento de projeto para o Centro Cultural Univates, localizado em Lajeado - RS. A metodologia empregada inclui uma revisão de literatura para a fundamentação teórica, e conta com o testemunho da equipe sobre aspectos biográficos, metodologia projetual e o estudo de caso, com base em entrevistas presenciais. Compreende-se que a longevidade do escritório se deve ao nível de excelência dos projetos que desenvolve e, portanto, o /STUDIOMDA constitui uma referência para os estudos sobre wayfinding design.

Palavras-chave: design de sinalização; design gráfico ambiental; design da informação.

\begin{abstract}
This research regards a design office in the south of Brazil, specialized in signage and wayfinding design. Based on the acknowledgment of a trajectory that accounts for twenty years of experience, the aim is to point out /STUDIOMDA's contribution for a design culture at the regional level, once it develops projects for diverse spaces and audiences, in the residential, commercial and cultural sectors. In order to exemplify the office's actuation, the analysis emphasizes the project development for Centro Cultural Univates, located in Lajeado - RS. The methodology includes a literature review for the theoretical basis, and counts on the team's testimony on biographical aspects, design methodology and the case study, based on face-to-face interviews. It is understood that the longevity of the office is due to the level of excellence of the projects that it develops and, therefore, /STUDIOMDA constitutes a reference for studies on wayfinding design.
\end{abstract}

Keywords: signage design; environmental graphic design; information design. 


\section{Introdução}

Este artigo apresenta o estudo sobre um escritório de design que contabiliza uma trajetória de vinte e cinco anos em projetos de sinalização e wayfinding. A empresa iniciou em 1993, e tornou-se /STUDIOMDA em $1996^{1}$. Com atuação a partir do estado do Rio Grande do Sul, o /STUDIOMDA Wayfinding Design desenvolve projetos para diversos setores, entre condomínios residenciais, espaços comerciais e culturais ${ }^{2}$. Ao estabelecer uma sede na Bélgica em 2016, o escritório passou a operar também no nível internacional. Destaca-se que a atuação ultrapassa o caráter mercadológico, pois são formadas parcerias com universidades e congressos para a realização de palestras e oficinas sobre as vivências do escritório. Em uma perspectiva didática, para além de seus clientes, a equipe difunde os conceitos de design gráfico ambiental, design de sinalização e wayfinding design junto a estudantes em aulas inaugurais e semanas acadêmicas ${ }^{3}$.

Este trabalho é parte de uma pesquisa sobre o desenvolvimento de projetos em design em âmbito regional. No estudo, são privilegiados os atores sociais que contribuem para a consolidação de uma cultura local de design, do período de industrialização ao cenário contemporâneo ${ }^{4}$. Logo, espera-se oportunizar uma reflexão sobre a contribuição do /STUDIOMDA para uma cultura de projeto no sul do país.

De modo a contextualizar o campo de atuação do /STUDIOMDA, a fundamentação teórica constitui um breve panorama sobre design de sinalização e wayfinding, com base em uma revisão de literatura. Em seguida, para o levantamento sobre os aspectos biográficos, método projetual e sobre o estudo de caso, foram realizadas entrevistas com a equipe. Por último, para elucidar a atividade do escritório, é apresentado um estudo sobre o projeto desenvolvido para o Centro Cultural Univates. O espaço compreende um teatro e uma biblioteca, e integra a Universidade do Vale do Taquari - Univates, em Lajeado - RS.

Os seguintes integrantes participaram do levantamento de dados: Luciana Mattiello, arquiteta e sócia-diretora, Manoela Medeiros, diretora administrativa, Gustavo Bassani, arquiteto e gerente de processos, e Eissom Fangueiro, designer. Atualmente, além das diretoras, duas designers coordenadoras e quatro estagiárias de design compõem a equipe. Assim, a análise é realizada a partir do olhar privilegiado dos profissionais, com depoimentos registrados em áudio e posteriormente transcritos ${ }^{5}$. A pesquisa iconográfica e documental foi feita com uma consulta ao portfolio da empresa e complementa o estudo.

\footnotetext{
${ }^{1}$ Nascida em Curitiba-PR em 1970, a sócia-diretora Luciana Mattiello graduou-se em Arquitetura e Urbanismo (UFRGS), em 1993. Especialista em Design Gráfico e Design Estratégico (Unisinos), em 2001 e 2005, respectivamente. O nome do escritório surge de uma abreviação para 'Mattiello Design e Arquitetura'.

${ }^{2}$ Entre os quais, destacam-se: parques (Ecoparque Sperry, em Canela - RS); instituições bancárias (Sicredi, em Porto Alegre, Teutônia e Sarandi - RS); indústrias (IRWIN do Brasil, em Carlos Barbosa - RS, Tramontina, em Recife - PE e Garibaldi - RS, Dimed, em Eldorado do Sul - RS, e Bomix, em Salvador - BA); instituições de ensino (Univates, PUCRS e rede Marista).

${ }^{3}$ Seminário Design-UFRGS, 2010 e 2013; Curso de Design de Interiores e Curso de Arquitetura-Feevale, 2013 e 2014 , respectivamente; Curso de Design-Univates, 2014; Design 360-APDesign, 2014; Curso de Arquitetura-Akashi National College of Technology, Japão, 2015; Curso de Design-Faculdade da Serra Gaúcha, março, 2015; Cursos de Design Gráfico e de Produto-Instituto Federal Sul Rio-Grandense (IFSul), 2015; Hasselt University, Bélgica, 2018.

${ }^{4}$ Os estudos anteriores trataram das trajetórias e projetos dos designers Norberto Bozzetti, Antonio Endler, Manlio Gobbi, os sócios José Carlos Bornancini e Nelson Ivan Petzold, além do escritório Verdi Design, e foram realizados em parceria com a Prof. Dra Maria do Carmo Curtis (UFRGS).

${ }^{5}$ As entrevistas foram realizadas em duas sessões, em abril de 2016, na sede do escritório em Porto Alegre-RS.
} 


\section{Do design de sinalização ao wayfinding design: uma breve revisão de conceitos}

Impõe-se considerar o espaço como território interdisciplinar de investigação, não porque seja objeto de estudo de várias áreas de conhecimento, mas porque sua complexidade demanda interpretações que decorrem da experiência humana tecida e tramada nas filigranas da vivência cotidiana, ou seja, não se pode pensar ou interpretar o espaço senão através da experiência cotidiana do homem que, no tempo e no espaço, o relaciona com suas criações. - Lucrécia D’Aléssio Ferrara, 2002.

Em seu estudo sobre as habilitações do design gráfico ambiental, Scherer (2014) especifica que a ambientação cria e dá forma aos lugares, enquanto o design de exposição tem o objetivo de educar e promover, e o design de sinalização, por sua vez, se utiliza de estratégias que direcionam, informam e identificam os espaços. Assim, encontrar o caminho certo, aprender e sentir-se bem no ambiente construído é de grande importância, pois determinada identidade é fortalecida, molda-se a percepção e a memória e desenvolve-se o senso de lugar. Portanto, projetos para o espaço físico animam, enriquecem e humanizam a vida. Nessas modalidades projetuais, o designer é responsável pela disponibilização gráfico-visual da informação (HESKETT, 2005; HUNT, 2003).

Sobre design de sinalização, a Associação dos Designers Gráficos - ADG (2000) afirma que pode ser definido como o planejamento, o projeto e a especificação de elementos gráficos no ambiente construído ou natural. Esses elementos são usados para comunicar informações específicas em sistemas de identificação, informação, direção, interpretação, orientação, regulamentação e ambientação. O design de sinalização procura melhorar e, por vezes, até viabilizar a utilização e o funcionamento dos ambientes (CALORI; VANDEN EYNDEN, 2015).

Conforme Velho (2007), embora os sistemas de sinalização mantenham as prerrogativas estético-formais funcionalistas, o projeto torna-se mais complexo ao incorporar novos atributos com a introdução da informática, tais como linguagem gráfica mais expressiva e maior liberdade na escolha de tipografias e cores. Nesse aspecto, um projeto de sinalização pode ser caracterizado pelo resultado da combinação de vários subsistemas: de informações, gráfico, físico/formal, construtivo, ambiental, normativo e de acessibilidade e segurança.

Por seu turno, Bastos (2004) aponta que a sinalização possui seis funções: identificar, orientar, informar, advertir, ambientar e particularizar. O sistema de sinalização modifica os espaços, pois organiza, valoriza, anima, ambienta e principalmente confere identidade e personalidade. Trata-se do design aplicado às necessidades de comunicação dos ambientes. É por este motivo que os projetos de sinalização devem ser parte integrante dos programas de identidade visual das organizações. Através da interação com o ambiente, o usuário constrói a imagem da empresa ou instituição. Sobre a relevância dessa modalidade projetual, vale citar o postulado do autor:

A sinalização eficiente é um sinal de respeito às pessoas que fazem uso dos espaços públicos e privados. Nós, os profissionais do desenho industrial, ou design, que, em certo sentido, somos responsáveis pela produção da cultura material da nossa sociedade, temos um papel fundamental na construção de um mundo mais planejado, mais humano e mais feliz. Precisamos ter clareza de nossa responsabilidade com a melhoria da qualidade de vida das pessoas e das organizações (BASTOS, 2004, p. 137).

Os principais elementos que constituem um projeto de sinalização são os pictogramas e setas, as cores e a tipografia, juntamente com os materiais e suportes. D'Agostini (2017) ensina que os pictogramas são informações de objetos ou conceitos traduzidos em forma gráfica 
simplificada. As cores são utilizadas para determinar setores, restringir ações e, também, alertar sobre procedimentos. Além das questões práticas de utilização e informação, a cor desempenha uma função estética no projeto. O uso da tipografia (palavras, frases, textos) transmite mensagens diretas (D'AGOSTINI, 2017).

No desenvolvimento de projetos em design gráfico ambiental, faz-se necessário aprofundar a compreensão acerca de wayfinding, pois a orientação espacial constitui fator determinante na experiência do público e no uso do ambiente construído. As características de cada um dos espaços, ou seja, a arquitetura, a distribuição dos elementos expositivos e de sinalização, a circulação e os fluxos, são fatores que interferem na orientação e na localização dos usuários. Nesse contexto, o sistema de wayfinding deve considerar o posicionamento e a diagramação das informações, o uso de cores e de materiais para criar espaços funcionais, confortáveis e cativantes, que oportunizem uma experiência significativa aos ocupantes (GIBSON, 2009).

Fernández e Fernández (2010) asseveram que um dos problemas mais estudados por arquitetos do movimento moderno, até meados do século $X X$, era a circulação nos ambientes. Le Corbusier e Mies van der Rohe preocuparam-se com o assunto ao considerá-lo em seus projetos. Desse modo, pensaram em espaços interiores flexíveis, a partir da modularidade dos ambientes. 0 termo wayfinding foi usado, pela primeira vez, em 1960, por Lynch (1997) considerando os mapas, as ruas, a sua numeração, os sinais direcionais e outros elementos como auxiliares na busca ou como a 'maneira de se encontrar' no espaço urbano. O seu trabalho é baseado no conceito da orientação espacial e o seu pré-requisito é a capacidade que o ser humano tem para desenvolver o mapa cognitivo, o qual o autor denomina 'imagem'.

Posteriormente, Arthur e Passini (1992) articularam o moderno conceito de wayfinding como um processo dinâmico para solucionar os problemas de mobilidade das pessoas no ambiente. No mesmo contexto, Berger (2005) emprega o termo wayfinding como orientação espacial ou a capacidade do ser humano de navegação. $O$ autor ressalta que

wayfinding não trata apenas de 'placas'. Trata sobre navegação em espaços complexos em uma integração de todas as formas de comunicação visual. Além da sinalização, os componentes de wayfinding podem incluir esculturas, marcos ou ícones, efeitos especiais de iluminação, estruturas arquitetônicas, materiais, cores, tecnologia e projeções de vídeo. Esses componentes devem estar integrados com as plantas-baixas e o orçamento do projeto em sua etapa inicial (BERGER, 2005, p. 110, tradução livre do autor).

Nesse aspecto, os itens mais importantes para um projeto de wayfinding são o planejamento espacial e a comunicação. A interação de ambos consiste na ordenação das informações para a tomada de decisão dos usuários, em um relacionamento dinâmico com o espaço, onde são levados em conta aspectos como percepção ambiental, circulação, fluxos, referências, marcos e, acima de tudo, a informação (VELHO, 2007).

Segundo Locatelli (2007), temos dois grupos de fatores que estão relacionados ao wayfinding: contextuais e composicionais. Os fatores contextuais são variáveis relacionadas ao ambiente, que influenciam na orientação espacial, sendo que as principais são: presença de marcos ou pontos de referência, dispositivos de sinalização e configuração espacial, ou seja, o sistema de relações espaciais e as suas formas, as organizações e os sistemas de circulação. Já os fatores composicionais são variáveis relacionadas ao indivíduo e que influenciam o comportamento dos usuários, de acordo com as suas características individuais. São elas: 
percepções, expectativas e avaliações quanto a espaços, levando em conta, entre outros elementos, faixa etária, gênero, cultura, nível socioeconômico, estilo de vida, experiência passada e grau de familiaridade com o ambiente.

Ao refletir sobre seu campo de atuação, a equipe do /STUDIOMDA salienta que, para o público geral, o termo 'sinalização' está associado às placas de rua. Então, em uma intenção didática, a estratégia é mostrar exemplos de projetos, a partir de uma apresentação e das informações disponíveis pelo website da empresa, no qual é mantido um blog ${ }^{6}$. Os projetistas mencionam que os autores divergem sobre o conceito de wayfinding, e retomam a definição de Lynch (1997): "a sinalização é saber onde se está e para onde se vai e wayfinding é tudo o que envolve essa modalidade projetual" ${ }^{7}$ (BASSANI; FANGUEIRO, 2016). Por sua vez, Mattiello (2016) acrescenta que costumam explicar a dimensão qualitativa do projeto, as suas vantagens, e o quanto pode gerar valor para o empreendimento. A diretora esclarece que, além da sinalização, pode-se fazer uma ambientação - ao invés de uma placa na parede, substituindo-a por uma pintura ou algum elemento especial, que sinalize de forma indireta, por exemplo.

\section{0 percurso do /STUDIOMDA: aspectos biográficos e metodologia projetual}

Em sua recordação sobre a trajetória do escritório, Mattiello (2016) menciona que, inicialmente, os projetos eram desenvolvidos com base em sistemas modulares de sinalização, importados dos Estados Unidos por uma empresa parceira situada no Rio de Janeiro ${ }^{8}$. Após compreender como proceder caso o suporte daquela empresa terminasse, a sócia-diretora passou então a estruturar métodos de trabalho a partir de desdobramentos da metodologia de arquitetura ${ }^{9}$.

Figura 1 - A identidade visual do escritório.

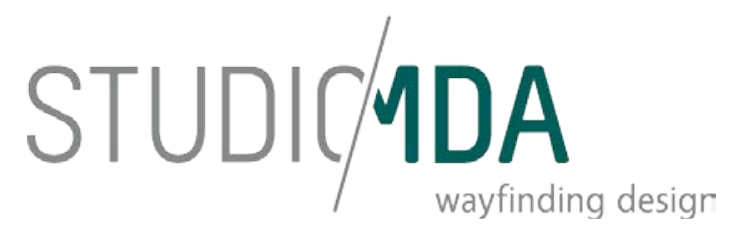

Fonte: arquivo /STUDIOMDA (2018).

\footnotetext{
${ }^{6}$ Ver <www.studiomda.com.br/blog> Acesso em: 20 mar. 2018.

${ }^{7}$ A equipe salienta que alguns autores e profissionais denominam design gráfico ambiental o que o escritório denomina wayfinding design, considerando-os sinônimos. Para a Society of Experiential Graphic Design - SEGD, associação estadounidense especializada, wayfinding é concebido como um tema comum às habilitações do design gráfico ambiental: sinalização, exposição e ambientação. O /STUDIOMDA compreende o design gráfico ambiental como um trabalho de ambientação, que também informa, expõe, orienta e sinaliza. Fangueiro (2016) salienta que há também os estudiosos que restringem o conceito de wayfinding a uma etapa do projeto, na qual, a partir do estudo dos fluxos e identificação dos pontos de decisão, marca-se a localização de placas em uma planta-baixa.

${ }^{8}$ Os sistemas modulares eram produzidos pela empresa americana APCO - Architectural Sign Systems, que segue atuante. Disponível em: <www.apcosigns.com> Acesso em: 20 mar. 2018.

${ }_{9}^{9}$ Mattiello (2016) cita a noção de tridimensionalidade, o controle sobre a viabilidade das peças como elementos em volume, desenhos técnicos, materiais e técnicas construtivas.
} 
Entre os primeiros projetos desenvolvidos nos anos 1990, trabalharam com a Calçados Beira Rio, de Novo Hamburgo, com o Blue Tree Towers, hotel em Porto Alegre, e com o Museu de Arte do Rio Grande do Sul - MARGS, que utiliza o sistema de sinalização modular até os dias atuais. O sistema do MARGS é interessante, pois no diretório geral ${ }^{10}$ utilizaram réguas que possibilitavam a troca de informações conforme exposições e atividades correntes, o que ofereceu flexibilidade e praticidade ao museu.

Embora esses projetos iniciais tenham sido bem-sucedidos, a equipe destaca as limitações do sistema modular, pois na época era complexo importar o material. Havia muitos problemas de alfândega no país, o material atrasava e perdia-se os prazos. Ainda assim, ressalta-se que o sistema permitia explorar a criatividade e era bastante flexível, e representou uma motivação para o escritório seguir na área do design de sinalização.

Após a experiência com os sistemas modulares, passaram para projetos personalizados, sendo que arquitetos de Porto Alegre começaram a buscar parceria com o escritório para desenvolver a sinalização dos empreendimentos que realizavam. Salienta-se o trabalho conjunto com o arquiteto Pedro Simch, com quem recentemente a equipe desenvolveu o projeto de wayfinding para o Grupo Dimed na sede de seu centro de distribuição, em Eldorado do Sul - RS. Outra parceria de longa data foi com o arquiteto Sergio Montserrat, com quem a equipe ressalta ter aprendido sobre modulação.

Nessa fase, Mattiello (2016) explica que havia diferentes áreas de atuação no escritório: arquitetura, sinalização, arquitetura comercial, identidade visual e design gráfico. Uma vez que designers passaram a ingressar na equipe, tomaram a decisão de não mais realizar projetos em arquitetura, pois estavam especializados em sinalização, e julgaram que valia a pena focar no design ${ }^{11}$. A diretora ressalta que o ingresso de designers possibilitou maior entendimento sobre tópicos como tipografia, pictogramas, e todos os elementos que integram o aporte desses profissionais.

Em seguida, passaram a aperfeiçoar o detalhamento técnico, em uma colaboração contínua entre arquitetos e designers. Ao final dos anos 1990, começaram a trabalhar com a Cia. Zaffari. Nessa época, também sinalizaram a Clínica Visão, cujo projeto continua instalado até atualmente $^{12}$. Também desenvolveram o sistema para o Moinhos Shopping e Hotel Sheraton ${ }^{13}$. Foi um trabalho de grande vulto, quando o /STUDIOMDA começou a ser reconhecido, pois os projetos de sinalização ainda eram incipientes em Porto Alegre. A figura 2 ilustra uma parte do portfolio da empresa. À esquerda, projeto para o Hipermercado Zaffari Wallig. Ao centro, projeto para o Hospital da Restinga e Extremo-sul. À direita, detalhe do projeto para o Museum Hof Van Busleyden, em Mechelen, Bélgica.

\footnotetext{
${ }^{10}$ O diretório é um tipo de elemento de sinalização.

${ }^{11}$ Sobre essa transição a partir da arquitetura, Mattiello (2016) afirma que estava um pouco insatisfeita com os projetos de longa duração e de grandes dimensões. A diretora explica que, no design de sinalização, ainda que na interação com projetos arquitetônicos, acaba-se "dando um zoom" mesmo que bidimensional, saindo da escala urbana e atuando no detalhe.

${ }^{12}$ Realizado em parceria com a arquiteta Leandra Saldanha.

${ }^{13} \mathrm{O}$ projeto de sinalização atual para o Moinhos Shopping é um redesign do anterior, e constitui o primeiro sistema bilíngüe que realizaram. Foi inspirado na identidade visual desenvolvida por Norberto Bozzetti, designer e professor atuante desde os anos 1960, sendo um pioneiro do design gráfico no sul do país, onde desenvolve projetos de identidade visual para diversos setores.
} 
Figura 2 - Amostra do portfolio.
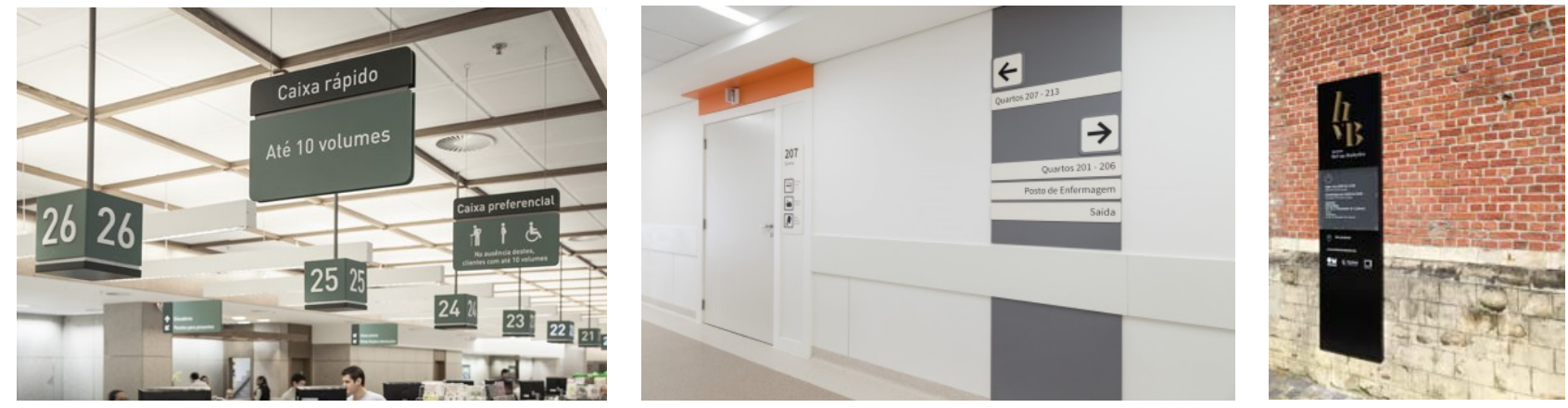

Fonte: arquivo /STUDIOMDA (2018).

No que se refere à contribuição para a consolidação de uma cultura de design local, Mattiello (2016) assevera que o escritório se depara com essa questão diariamente:

\begin{abstract}
Fazemos trabalhos conceituais que exigem processo, tempo e envolvimento, pessoas talentosas e o investimento em ideias e criação. A decisão de ir além da meta financeira se torna difícil para a manutenção de uma empresa no mercado, pois pode parecer um pouco romântico. Porém, todas as pessoas que trabalham no /STUDIOMDA acreditam nesse tipo de valor. É aí que estamos situados: não trabalhamos fazendo qualquer projeto, em poucos dias. Precisamos de tempo [...] Nossos projetos passam por muitas revisões e muitos detalhes, para que no final o resultado saia como pretendíamos e também de acordo com as expectativas dos clientes (MATTIELLO, 2016).
\end{abstract}

Em seu comentário sobre o mercado, Bassani (2016) esclarece sobre as dificuldades para o maior aprofundamento para a realização de projetos. O gerente explica que, para obter sucesso, o planejamento é a chave para uma boa execução. No entanto, ao considerar os escritórios de design em uma perspectiva geral, o profissional considera que o tempo de planejamento é usualmente sacrificado, pois parte-se mais rapidamente para a execução, com o resultado ficando à margem do esperado. Bassani (2016) defende a necessidade de um tempo mínimo de projeto, ainda que o mercado seguidamente responda que algum profissional desenvolve o mesmo trabalho muito mais rapidamente. Porém, informa que os resultados serão diferentes.

Sobre as atribuições da equipe, Mattiello (2016) destaca o perfil do /STUDIOMDA: todos os integrantes fazem parte de todo o processo. Os profissionais participam do briefing, desenvolvem os projetos, e coordenam os processos internos e de relação com o cliente. A diretora considera este aspecto positivo, pelo fato de se tratar de um pequeno escritório: todos tem conhecimento dos projetos que estão em andamento, contribuem com opiniões sobre o que está sendo feito e auxiliam a resolver determinado problema. Nesse sentido, a respeito de um perfil profissional para integrar a equipe do /STUDIOMDA, Mattiello (2016) fornece pistas sobre as competências que espera encontrar no designer:

Quando recrutamos novos profissionais para o escritório, sempre me concentro nas pessoas. Isto porque, quando recebemos o currículo, o portfolio, conseguimos visualizar quando se trata de alguém talentoso, organizado, com potencial, é criativo, se preocupa com a modulação, com as proporções, com o conceito etc. Porém, o que me interessa nas pessoas são elas mesmas: a expectativa para a vida, se realmente tem uma preocupação mais humana, se o interesse é de fato colaborar, fazer parte de uma equipe, crescer, aprender e ensinar. Além de um portfolio robusto e diferenciado, o mais importante hoje é as pessoas (MATTIELLO, 2016). 
A diretora salienta que, pelo fato de passarem muito tempo juntos, se importa em trazer pessoas que possam agregar e se integrar no escritório: "gente mesmo", pois os softwares utilizados se aprendem em um curto período. Assim, os profissionais com esse olhar são interessantes, porque eles irão trabalhar com o propósito de transformar o projeto em algo mais humano. Afinal, trata-se de um trabalho feito para as pessoas:

\begin{abstract}
O mínimo que o profissional deve ter é essa percepção sobre o outro. Eu penso que sensibilidade é a principal característica de um designer. Compreendo que a técnica é importante e somos treinados para isso, mas ser sensível, intuitivo e humano certamente são diferenciais. Existe uma desvirtuação no mercado pelo dinheiro, pela fama e pelos prêmios. Como afirma o sociólogo Zygmunt Bauman (2001), na modernidade líquida é tudo tão rápido, tão prático, tão brilhante e tão famoso que não sobra nada (MATTIELLO, 2016).
\end{abstract}

Com efeito, essas competências refletem em uma metodologia própria para o desenvolvimento de projetos em wayfinding. Nesse aspecto, Bassani e Medeiros (2016) destacam que investem na etapa de diagnóstico e análise do problema: reuniões de briefing, estudo do projeto arquitetônico e complementar, discussões com equipes de operação e usuários. Acrescentam que, ao visitar a obra, a equipe formata a própria impressão sobre as necessidades. Após a apresentação da interpretação do briefing, passam para o anteprojeto, que inclui estudo de fluxos e estratégia de circulação, além da elaboração do conceito gráfico-visual. Depois da aprovação do cliente, desenvolvem o projeto executivo, com o detalhamento técnico das peças. Finalmente, supervisionam a etapa de instalação, certificando-se que o resultado esteja fiel ao projeto realizado. A figura 3 resume a metodologia empregada para o desenvolvimento de projeto. A imagem à esquerda representa o estudo sobre as características do local (arquitetura, identidade de marca e fluxos) e sobre o público que o utiliza. Ao centro, a realização de estudos conceituais e definição da alternativa mais funcional, segura, personalizada e adequada para o ambiente. À direita, a entrega do plano de execução detalhado e acompanhamento da implementação do sistema para garantir o melhor resultado.

Figura 3 - Síntese do método projetual.
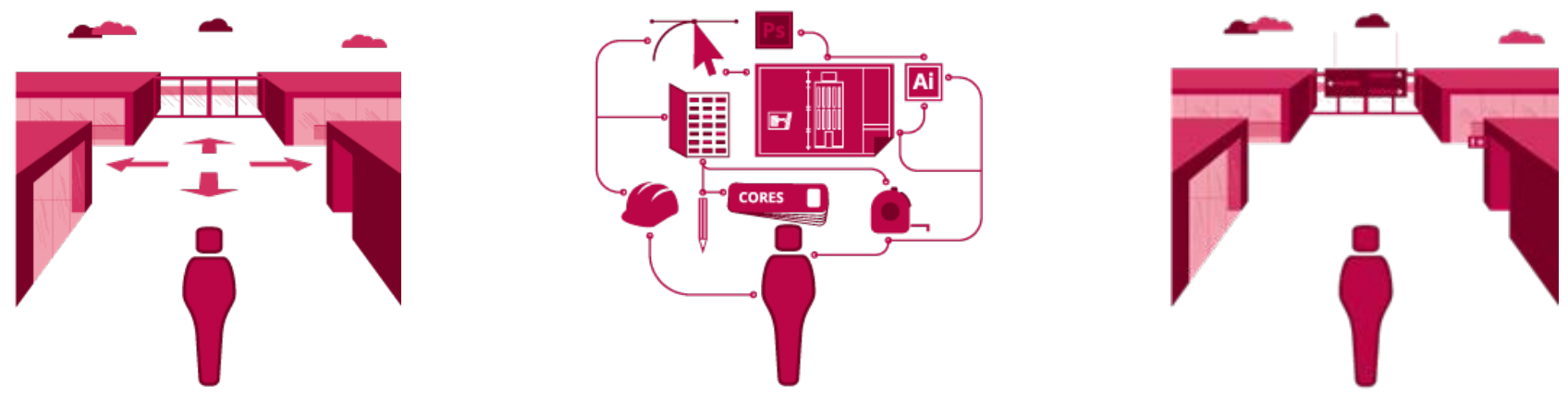

Fonte: arquivo /STUDIOMDA (2018).

Ainda sobre o método que elaborou ao longo dos anos, Mattiello (2006) pondera que ocorrem alguns desvios de rota, e que podem ser produtivos. Muitas vezes, o que não é dito é mais importante do que as informações que são formalmente repassadas para a equipe. Torna-se estratégico observar além do óbvio e vislumbrar caminhos diferentes do esperado, e é aí que o 
projeto ganha qualidade e diferença, pois são buscadas soluções que estão de acordo com a interpretação do briefing, o que geralmente surpreende o usuário e o cliente de maneira positiva.

A respeito das particularidades do briefing na área do wayfinding design, a equipe cita o conceito do espaço, as características do público, aspectos da interação do usuário com o espaço construído, além de orientação, pontos de acesso, segurança, e necessidades específicas de carga e descarga. O escritório possui experiência em simplificar as questões de funcionamento e operação de qualquer tipo de empreendimento. Por isso, não devem ser chamados apenas no final da construção. Quando participam desde o início da obra, conseguem atuar na raiz da questão e simplificar o processo, e até mesmo intervir junto ao conceito da arquitetura, de modo a integrar o sistema de wayfinding aos espaços. Ainda no que se refere à relação com a arquitetura, os profissionais compreendem o wayfinding design como um complemento para o funcionamento dos ambientes (BASSANI; FANGUEIRO; MATTIELLO; MEDEIROS, 2016).

Durante a fase de anteprojeto, a equipe informa que são construídos protótipos sempre que possível, o que auxilia o entendimento por parte do cliente ${ }^{14}$. Nesse aspecto, segundo os profissionais, por mais que um modelo tridimensional feito via software seja pertinente, é quando o cliente tem contato com o material, podendo tocar e analisar as dimensões, que aprofunda-se a compreensão sobre o trabalho. De modo a exemplificar a atuação do escritório, a análise sobre a proposta de wayfinding design para o Centro Cultural Univates é de interesse para o estudo.

\section{0 projeto de wayfinding para o Centro Cultural Univates}

No que se refere ao briefing para o projeto de wayfinding para o Centro Cultural Univates, a equipe menciona o estágio avançado da obra, e o objetivo de internacionalização da universidade. Havia a necessidade de uma nova biblioteca, de maior capacidade, e um teatro, até então inexistente para receber grandes espetáculos na região do Vale do Taquari. Partiu-se do entendimento que o novo centro cultural seria um local transformador para a comunidade acadêmica e para a cidade. Nesse aspecto, Fangueiro (2016) salienta que o cliente almejava mostrar que era possível receber eventos e contribuir para o desenvolvimento regional. Embora a Univates seja uma instituição privada, seu equipamento cultural seria um bem público para a comunidade.

De acordo com Bassani (2016), o projeto de wayfinding deveria reforçar as singularidades do projeto arquitetônico e do ambiente ${ }^{15}$. 0 edifício se localizava no topo de um morro com vista privilegiada, já utilizado anteriormente pela comunidade, como uma praça. O prédio é composto por dois blocos, com o teatro entre os maiores do estado. O outro bloco é a biblioteca, com necessidade física de circulação e armazenamento de livros, além de uma área de salas de estudo. O entorno conta com uma praça seca e uma escadaria onde as pessoas sentam no final de semana, escutam música e tomam chimarrão, com vista para a cidade. O prédio fica no centro do campus universitário e liga todos setores. Portanto, o projeto buscou uma adequação ao ambiente cultural com funcionalidade e elegância, considerando as atribuições de uma biblioteca e de um teatro. Bassani e Fangueiro (2016) salientam que as especificidades do espaço e do público

\footnotetext{
${ }^{14}$ Quando estão realizando os desenhos iniciais, estudando proporções dos elementos e tamanhos de texto, costumam construir mocapes, para testes que antecedem a apresentação do protótipo ao cliente.

${ }^{15} \mathrm{O}$ projeto arquitetônico é de autoria da Tartan Arquitetura.
} 
possibilitaram trabalhar a informação de modo mais lúdico, pois as pessoas tem um conhecimento prévio sobre as funções daquela tipologia de edifício e, portanto, esperavam encontrar mezanino, plateia alta e baixa, sanitários e chapelaria.

A equipe criou também a identidade visual do complexo. Durante a etapa de pesquisa, estudaram como os profissionais utilizam a arquitetura como prerrogativa estético-formal para projetos de identidade visual e de sinalização. Partiram dos dois volumes básicos do prédio (teatro e biblioteca) que simplificaram, cruzaram todas as formas e funções, com a utilização de uma linha curva para representar o terreno acidentado, que também constitui um elemento de ligação, para a criação do símbolo. Acrescentaram o logotipo da Univates e outra fonte tipográfica para o designativo 'centro cultural'. Utilizaram cores para a diferenciação entre o designativo nas submarcas para o teatro e para a biblioteca, o que posteriormente foi seguido pelo sistema de sinalização. Assim, elaboraram um jogo de cores pré-programado, para realizar uma variação conforme a necessidade de aplicação. Com a identidade visual aprovada (figura 4), partiram para o projeto de wayfinding.

Figura 4 - O edifício do Centro Cultural Univates e a identidade visual.
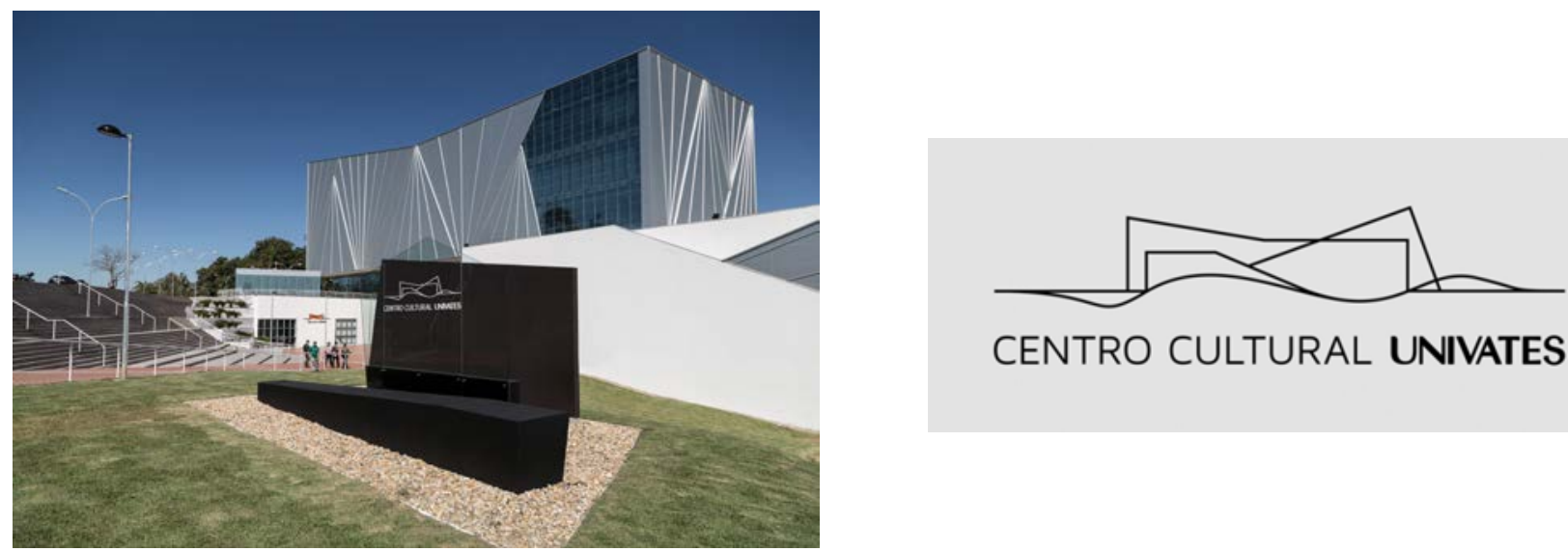

CENTRO CULTURAL UNIVATES

Fonte: arquivo /STUDIOMDA (2018).

O contorno da arquitetura, cujo traçado é linear e o contorno irregular, inspirou um sistema de placas e pictogramas específicos, de acordo com a função e uso do espaço. Fangueiro (2016) considera que, por se tratar de um centro cultural em uma universidade, onde provavelmente o público tem maiores referências visuais, é possível se utilizar de maior liberdade para explorar a abstração ${ }^{16}$. Por sua vez, Bassani (2016) ressalta que cada elemento teve vários estudos de croquis e de proporções para que fosse legível nas duas aplicações, no contraste entre positivo e negativo.

A tipografia segue o conceito com diferentes pesos e usos. Sobre a tipografia em sistemas de sinalização, Fangueiro (2016) adverte que dificilmente optam por fonte com serifa. Neste caso, porém, era pertinente, pois queriam reforçar o conceito da 'palavra', com uma linguagem visual que remete ao clássico e à formalidade de uma instituição de ensino. Ao mesmo tempo, sem que a proposta deixasse de ser visualmente moderna, pois a tipografia escolhida tem a serifa

\footnotetext{
${ }^{16} \mathrm{O}$ designer explica sobre a possibilidade de customização, em contraponto ao padrão de pictogramas do sistema AIGA - American Institute of Graphic Arts, já consolidado. Ver <www.aiga.org>. Acesso em: 20 mar. 2018.
} 
quadrada, que se relaciona com as linhas do logotipo. Bassani (2016) explica que, em determinada etapa, costumam apresentar ao cliente o conjunto de pictogramas, setas e tipografia, e que não necessariamente deve-se utilizar a mesma tipografia da identidade visual. 0 importante é que o texto seja legível e reforce o conceito, conforme a figura 5.

Figura 5 - O sistema gráfico e aplicação.

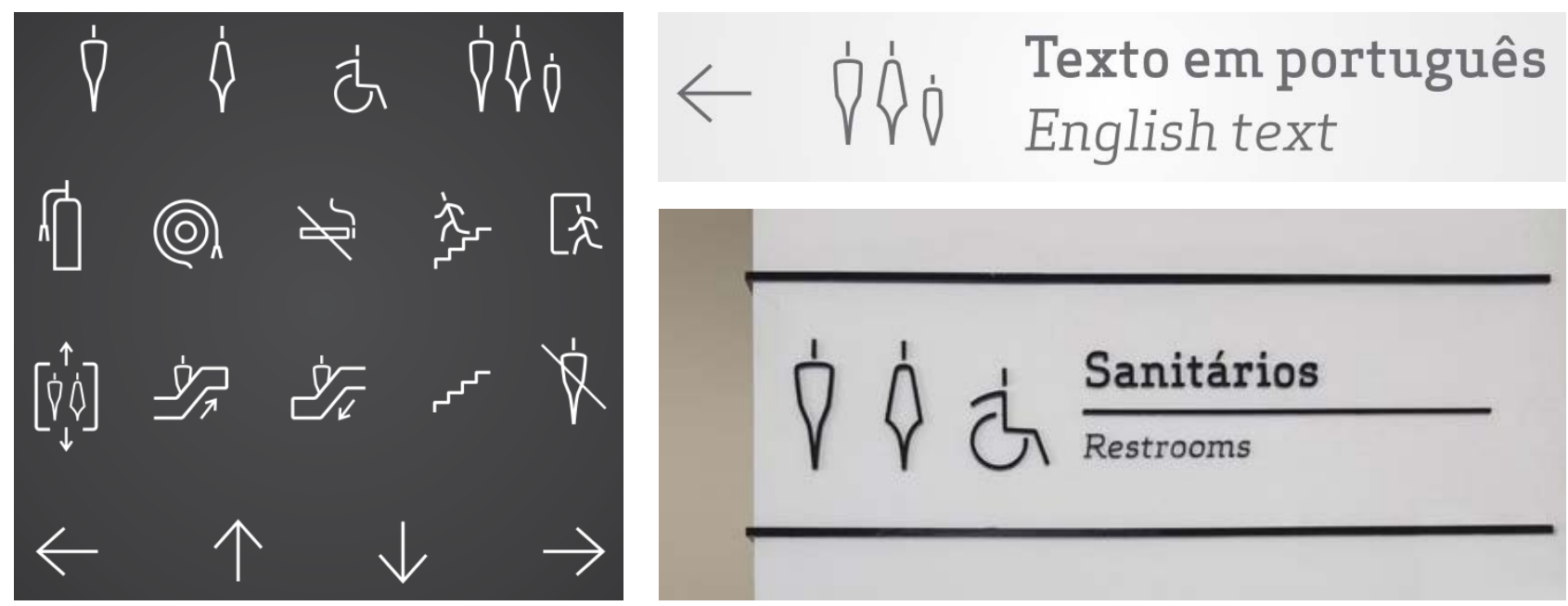

Fonte: arquivo /STUDIOMDA (2018)

$\mathrm{Na}$ fase de planejamento, participaram da distribuição dos espaços, bem como a identificação dos pontos de decisão, e na setorização auxiliaram a nomear os pavimentos, além de criarem a codificação de cores. Há uma cor predominante, que é a entrada do teatro, além da cor para o acesso da biblioteca, e um acesso secundário que é o da praça seca em outro nível. 0 acervo da biblioteca não é dividido entre áreas do conhecimento, tais como exatas e humanas, mas pelo seu padrão cromático. No teatro, pelo contrário, há uma função bem específica: um ambiente de pouca luz, em que a sinalização necessitava ter contraste mas, ao mesmo tempo, precisava ser sóbria para não chamar mais atenção que o espaço arquitetônico. Então, utilizaram uma única cor, o marrom. Assim, Mattiello (2016) assevera que, com o projeto de wayfinding, puderam contribuir com a facilidade de operação, desde a venda de tíquetes online à localização das poltronas, bem como a codificação dos livros da biblioteca.

Sobre materiais e acabamentos, escolheram o acrilato (acrílico com textura jateada). Preocuparam-se com a racionalização da execução e, por isso, se restringiram ao acrílico e ao adesivo vinílico, em uma estrutura metálica com tinta automotiva, além de vidro e concreto para as bases externas. Nos ambientes internos, aplicaram paineis detalhados nos pontos de decisão, cujas formas foram definidas a partir das linhas da arquitetura. Os paineis foram feitos em MDF medium density fiberboard, com rebaixo que remete à fachada do empreendimento. Com base no estudo das linhas, criaram uma peça-mãe vinculada à arquitetura da fachada. A informação em preto compôs com o fundo para marcar a cor do substrato. $\mathrm{O}$ acrílico foi aplicado diretamente na parede, para não competir com a arquitetura. As placas de porta seguiam a linguagem da peçamãe, bem como a marcação das salas de estudo coletivo. Na figura 6 , à esquerda, o totem externo. Ao centro, placa direcional. À direita, o diretório da biblioteca. 


\section{Artigo Completo}

Figura 6 - Elementos do sistema de sinalização do Centro Cultural Univates.
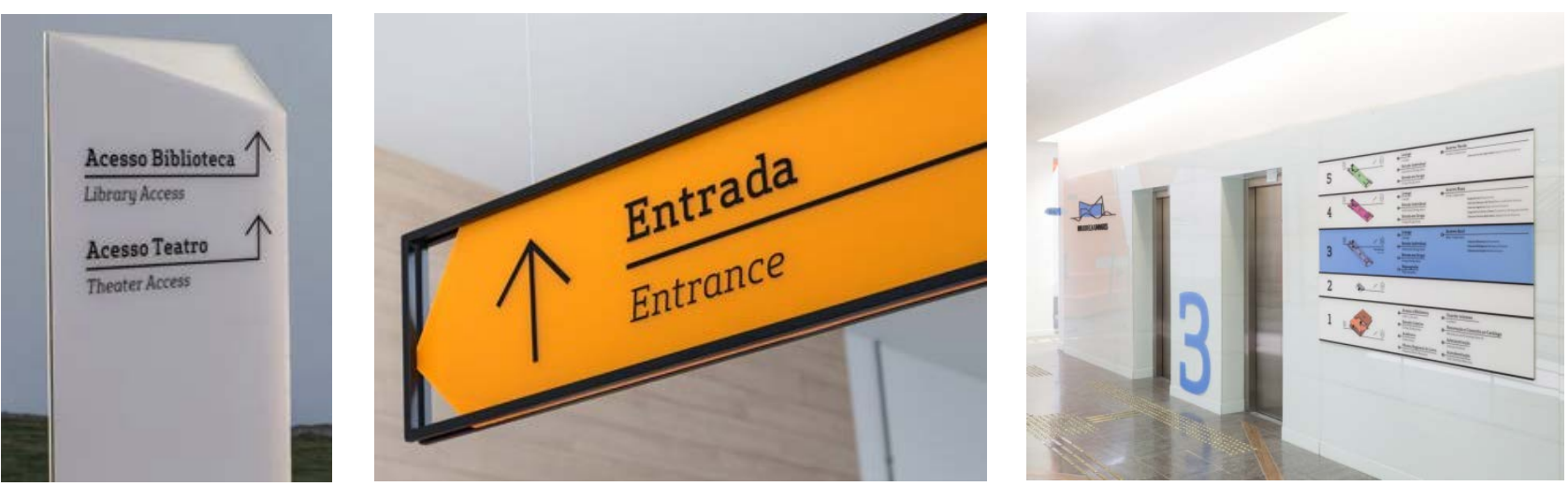

Fonte: arquivo /STUDIOMDA (2018).

$\mathrm{Na}$ biblioteca, auxiliaram na marcação do atendimento e distribuição do acervo. A peça principal do acesso à biblioteca apresentava este setor ao usuário e indicava as cores do acervo em cada pavimento. Criaram uma planta em perspectiva, identificando os espaços principais, sendo que desenharam a planta em conjunto com o escritório de arquitetura, conforme as funções dos ambientes ${ }^{17}$. Estava prevista uma aplicação em adesivo no piso, porém foi descartada em função da acessibilidade, com a colocação de piso tátil. A edificação recebeu um projeto completo de acessibilidade, que foi incorporado ao wayfinding, com leitura em braile nas placas de porta.

A marca do empreendimento foi aplicada nas duas fachadas, de acordo com cada uma das funções e com a utilização das cores principais: na biblioteca, o laranja e no teatro, o marrom. 0 teatro segue uma cor padrão para aplicação dos totens e placas direcionais nas paredes, considerando os direcionamentos das plateias e, também, nos elevadores (diretório de elevador). Na sinalização externa, criaram uma peça de apresentação do empreendimento: um totem em acrílico com base de concreto, visível por todos os que circulam, inclusive para fotos, pois o centro cultural viria a ser também um local para a realização de formaturas. Por isso, a base de concreto é um assento posicionado estrategicamente em integração com o espaço físico.

Em sua reflexão sobre o resultado, Fangueiro (2016) afirma que a forma recortada das peças confere dinamismo, pois dependendo de como são visualizadas, são percebidas de modos diferentes, sem nunca deixar de se conectar ao sistema, além de se diferenciar do formato retangular usual. Bassani (2016) explana que o sistema é composto por uma estrutura tubular metálica com acrílico. Cada peça é formada por dois quadros em acrílico com adesivo no meio, para evitar a transparência que dificultaria a leitura, de modo que a informação não apareça dos dois lados. A fixação é feita com fita dupla face, sendo que em portas de vidro colocaram um adesivo no lado oposto para cobrir a fita. Também criaram um porta-cartaz e um painel adesivo para os artistas deixarem suas assinaturas.

No que se refere ao formato pouco usual das peças, Fangueiro (2016) destaca que

\footnotetext{
17 Sobre esta integração do wayfinding design com a arquitetura, mencionam a necessidade de aceitação do arquiteto, e salientam que o profissional deve estar ciente que não poderá modificar o espaço posteriormente como, por exemplo, alterar um revestimento, porque há outro projeto vinculado. Portanto, as duas equipes devem estar alinhadas.
} 
romperam com a convenção das placas ortogonais e de ângulos retos, ainda que fosse possível seguir o mesmo recorte para cada uma, com uma variação para tipos diferentes de placas, por exemplo, entre as placas locacionais e as direcionais. Isso evitaria o alto custo, caso o sistema tivesse mais tipos diferentes de placas. Como resultado, a alternativa confere um efeito ótico interessante, como ilustra a figura 7.

Figura 7 - Aspectos do sistema de wayfinding para o Centro Cultural Univates.
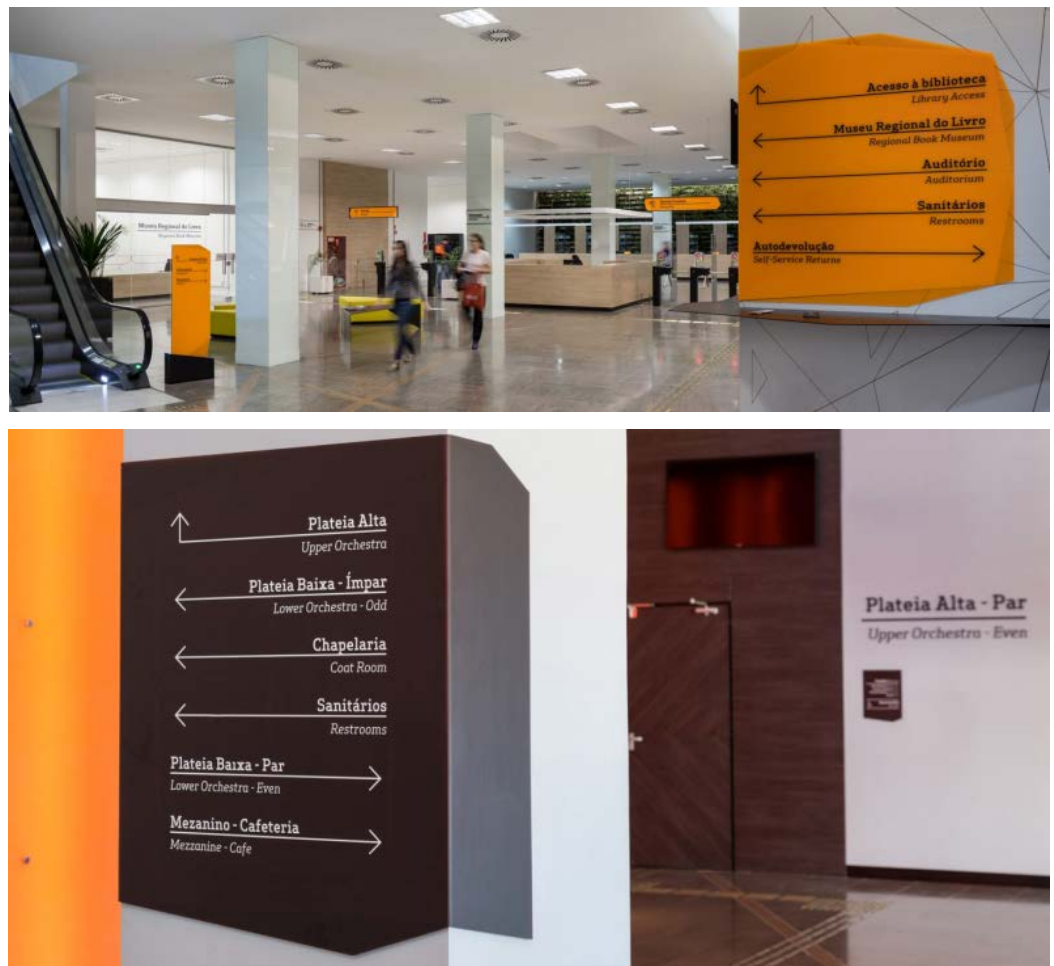

Fonte: arquivo /STUDIOMDA (2018).

A qualidade do projeto é atestada pelo depoimento de Rodrigo Brod, professor e coordenador do Curso de Design da Univates:

O Centro Cultural Univates se transformou em um verdadeiro marco para a cidade e um delineamento claro das intenções da instituição de ensino superior em relação à valorização do conhecimento, das artes e da cultura. Nesse contexto, o projeto de wayfinding, idealizado e executado pelo /STUDIOMDA não poderia apenas servir ao propósito funcional - que cumpre magnificamente, por sinal - mas deveria se comportar como parte indissociável da linguagem do projeto. Através dos elementos construídos e dos espaços de circulação, há uma voz sempre presente, marcante, identitária, representada pelos elementos da sinalética, que não são apenas um coadjuvante no conjunto, mas parte desse organismo que respira cultura e conhecimento (BROD, 2016).

A proposta de wayfinding design para o Centro Cultural Univates foi desenvolvida durante três meses, entre 2013 e 2014. Salienta-se que o projeto foi 3 lugar na categoria Design GráficoVisual do Prêmio Bornancini ${ }^{18}$, em 2014.

\footnotetext{
${ }^{18}$ O Prêmio Bornancini é organizado bianualmente pela Associação dos Profissionais em Design do Rio Grande do Sul
} - Apdesign, e sua sexta edição ocorreu em 2016. Ver <www.premiobornancini.com.br>. Acesso em: 20 mar. 2018. 


\section{Considerações Finais}

A borboleta Monarca é distinta não só por seu belo padrão de cores, mas também por seu misterioso senso de orientação. Milhares delas migram no inverno para um destino específico sem nunca ter feito o percurso antes. Isso é o que buscamos com nossos projetos: permitir que as pessoas entendam e utilizem ambientes sem precisar conhecêlos. - Texto de apresentação do /STUDIOMDA. Grifos mantidos conforme o original.

Com base neste estudo, compreende-se que, em wayfinding design, desenvolve-se a estratégia de circulação, estuda-se o ambiente e o público que irá utilizá-lo. Nas palestras que profere em universidades e congressos, de modo a destacar a interface entre arquitetura e design, a sócia-diretora do escritório costuma exemplificar com o espaço do aeroporto. Sem a sinalização, não é possível circular, acessar o portão de embarque e localizar o voo. Ou seja, o wayfinding design tem uma atribuição fundamental na vida cotidiana.

O sistema de sinalização é uma parte do trabalho do /STUDIOMDA, sendo que a essência do projeto é outra. Em consonância com o que postulou Berger (2005) anteriormente, a intervenção é mais estratégica e de inteligência do que apenas projetar uma série de placas. Confere-se identidade aos espaços, valorizando os aspectos comunicacionais dos ambientes. Assim, é possível estabelecer um nexo com o que ensina Niemeyer (2008): o objetivo do design é resolver os problemas de diálogo das pessoas com os outros e consigo mesmo. No caso dos projetos de wayfinding desenvolvidos pelo /STUDIOMDA, a tarefa é resolver o diálogo entre as pessoas e os espaços nos quais circulam.

Além de fortalecer a identidade dos ambientes e a relação de pertencimento das pessoas com os espaços, o wayfinding design possibilita aprimorar os aspectos operacionais das instituições. $O$ caso do Centro Cultural Univates é emblemático, pois demonstra que o trabalho do designer transcende a intervenção meramente cosmética - ideia que, no projeto analisado, pode ser corroborada a partir de uma futura avaliação junto aos usuários. A concepção sobre o papel do profissional pode ser observada na fala da sócia-diretora em relação ao ensino do design:

\footnotetext{
O design pode ser uma ferramenta de mudança cultural, mas depende da academia também. Como os estudantes estão saindo da universidade hoje? Eu vejo uma geração, com exceções, de pessoas que não tem essa consciência. Acredito que o designer tem potencial de transformação, que pode fazer o bem para a sociedade. 0 design hoje está muito além do produto. No nosso caso, temos uma responsabilidade muito grande: podese evitar acidentes, fazer com que a pessoa não perca um avião, intencionalmente transformar a circulação das pessoas no lugar que está sendo projetado, e em todas as áreas do design se tem esse tipo de responsabilidade (MATTIELLO, 2016).
}

Em outras palavras, Mattiello (2016) reflete sobre aspectos sociais da atividade, cujos parâmetros são válidos também no âmbito do wayfinding design. Ao citar Bauman (2001) quando traça as competências almejadas e o perfil profissional para integrar a equipe, com ênfase na sensibilidade para tornar o ato projetivo mais humano, a sócia-diretora pontua a dimensão ética do design. Assim, o escritório opta por se manter em uma linha de pensamento que se faz necessária diante do contexto atual, de crise socioeconômica e de relações soltas nas dimensões de tempo e espaço.

Em última análise, compreende-se que a pertinência do design gráfico ambiental consiste em humanizar os ambientes, para que as pessoas encontrem o caminho para seus destinos, aprendam e sintam-se bem nos espaços. Desse modo, valida-se a hipótese inicial: a contribuição 
do /STUDIOMDA para uma cultura de design advém do nível de excelência dos projetos que desenvolve para diversos setores em uma longeva trajetória, tendo a humanização dos espaços como elemento norteador em wayfinding.

\section{Referências}

ASSOCIAÇÃO DOS DESIGNERS GRÁFICOS - ADG. ABC da ADG. São Paulo: ADG, 2000.

ARTHUR, P.; PASSINI, R. Wayfinding People, Signs, and Architecture. New York: McGraw-Hill, 1992.

BASSANI, G. Sobre o escritório e projetos. Entrevista ao autor. Porto Alegre, abril de 2016.

BASTOS, R. Sinalização: a comunciação visual a serviço dos ambientes. In: Pensando Design. MAGALHÃES et. al. (Org.). Porto Alegre: Uniritter, 2004.

BAUMAN, Z. Modernidade Líquida. Rio de Janeiro: Zahar, 2001.

BERGER, C. M. (Org.). Wayfinding: designing and implementing graphic navigational systems. Hove: Rotovision, 2005.

BROD, R. Sobre o projeto para o CCU. Depoimento enviado por email ao autor, 2017.

CALORI, C.; VANDEN EYNDEN, D. Signage and Wayfinding Design: a complete guide to creating environmental graphic design systems. New Jersey: John Wiley \& Sons, 2015

D’AGOSTINI, D. Design de Sinalização. São Paulo: Blucher, 2017.

FANGUEIRO, E. Sobre o escritório e projetos. Entrevista ao autor. Porto Alegre, abril de 2016.

FERRARA, L. D. Design em espaços. São Paulo: Rosari, 2002.

GIBSON, D. The Wayfinding Handbook: information design for public places. San Francisco: Chronicle Books, 2009.

HESKETT, J. El Diseño en la Vida Cotidiana. Barcelona: Gustavo Gili, 2005.

HUNT, W. Environmental Graphics: Projects and Process. NY: Harper Design International, 2003.

LOCATELLI, L. Orientação Espacial e Características Urbanas. Dissertação de mestrado. Universidade Federal do Rio Grande do Sul - UFRGS, Porto Alegre, 2007.

LYNCH, K. A Imagem da Cidade. São Paulo: Martins Fontes, 1997.

MATTIELLO, L. Sobre o escritório e projetos. Entrevista ao autor. Porto Alegre, abril de 2016.

MEDEIROS, M. Sobre o escritório e projetos. Entrevista ao autor. Porto Alegre, abril de 2016.

NIEMEYER, L. Design Atitudinal: uma abordagem projetual. In: Design Ergonomia Emoção. MONT'ALVÃO, C.; DAMAZIO, V. (Orgs.) Rio de Janeiro: Mauad X FAPERJ, 2008.

SCHERER, F. Design gráfico ambiental: revisão e definição de conceitos. In: 11 Congresso Brasileiro de Pesquisa e Desenvolvimento em Design - P\&D Design. Gramado: UFRGS, 2014.

VELHO, A. L. O. L. O design de sinalização no Brasil: a introdução de novos conceitos de 1970 a 2000. Dissertação de mestrado. PUC-Rio, Rio de Janeiro, 2007. 